\title{
EVALUATION OF THE SOCIAL IMPLICATION PERCEPTION OF HEALTHCARE EMPLOYEES IN THE COVID- 19 OUTBREAK PROCESS
}

\author{
DOI: 10.17261/Pressacademia.2020.1251 \\ PAP- V.11-2020(23)-p.115-120
}

\section{Perihan Eren Bana}

Istanbul Yeni Yuzyıl University, Helath Services Vocational School, Istanbul, Turkey. perihanabana@gmail.com, ORCID: 0000-0002-5139-5327

To cite this document

Eren-Bana, P., (2020). Evaluation of the social implication perception of healthcare employees In the COVID-19 outbreak process. PressAcademia Procedia (PAP), V.11, p.115-119

Permanent link to this document: http://doi.org/10.17261/Pressacademia.2020.1251

Copyright: Published by PressAcademia and limited licensed re-use rights only.

\begin{abstract}
Purpose- There is various evidence in the literature that healthcare workers also face the risk of stigmatization during the epidemic, in which they work with great devotion. In this study, in line with the literature, it is aimed to evaluate the perception of healthca re professionals about social stigmatization in the epidemic process and to reveal the risks in this regard.

Methodology-In order to evaluate the social stigma perception of healthcare professionals, a measurement tool specific to this study was created. The research was carried out through the questionnaire created electronically, reaching a total of 151 participants. The data obtained were analyzed with IBM SPSS 24.0 package program. The total reliability value of the scale is 0.86 , and the reliability values for social stigma, professional dignity, exclusion and witnessing stigma are respectively; $0.91 ; 0.89 ;$ It is 0.74 and 0.75 .

Findings- In addition to the professional reputation dimension, there is a moderate and positive relationship between the sub-dimensions of the scale. Another finding obtained in the scope of the research is that healthcare professionals experience $51.2 \%$ social stigma. T-test results show that there is no difference in scale total score and sub-dimensions according to gender and marital status, and ANOVA Test results show that there is no difference in the same variables according to age groups and educational status ( $p>0.05)$.

Conclusion- It is thought that studies should be conducted to improve the sense of self for healthcare professionals in order to decrease the perception of social stigmatization, which has a very negative impact in the long term. It should not be forgotten that it is extremely important to reduce the negative emotions and thoughts in the healthcare professionals who are the main actors in maintaining the quality of service in the process of providing health services.
\end{abstract}

Keywords: COVID-19, pandemic, healthcare worker, social stigma.

JEL Codes: I12, I14, I18

\section{COVID-19 SALGINI SÜRECINDE SAĞLIK ÇALIŞANLARININ SOSYAL DAMGALANMA ALGISININ DEĞERLENDIRILMESI}

\section{ÖZET}

Amaç- Sağlık çalışanlarının büyük bir özveriyle çalıştıkları salgın sürecinde damgalanma riskiyle de karşı karşıya kaldıkları yönünde literatürde çeşitli kanıtlar bulunmaktadır. Bu çalışmada literatür bilgisi doğrultusunda sağlık çalışanlarının salgın sürecinde sosyal damgalanmayla ilgili algısını değerlendirmek ve bu konudaki riskleri ortaya koymak amaçlanmıştır.

Yöntem- Sağlık çalışanlarının sosyal damgalanma algısını değerlendirmek amacıyla bu çalışmaya özgü bir ölçme aracı oluşturulmuştur. Araştırma elektronik ortamda oluşturulan anket formu aracılı̆ıyla gerçekleştirilmiş, toplamda 151 katılımcıya ulaşımıştır. Elde edilen veriler IBM SPSS 24.0 paket programı ile analiz edilmiştir. Ölçeğin toplam güvenilirlik değeri 0,86 olup, sosyal damgalanma, mesleki saygınlık, dışlanma ve damgalanmaya şahit olma boyutları için güvenilirlik değerleri sırasıyla; 0,91; 0,89; 0,74 ve 0,75 şeklindedir.

Bulgular- Ölçeğin alt boyutları arasında mesleki saygınlık boyutu dışında genel olarak boyutlar arasında orta düzeyde ve olumlu yönde ilişki bulunmaktadır. Araştırma kapsamında elde edilen diğer bulgu, sağlık çalışanlarının \% 51,2 oranda sosyal damgalanma yaşadığı yönündedir. Yapılan T-testi sonuçları ölçek toplam puanı ve alt boyutlarında cinsiyete ve medeni duruma göre farklıık bulunmadığını, ANOVA Testi sonuçları da aynı değişkenlerde yaş gruplarına ve eğitim durumuna göre farklılaşma olmadığını göstermektedir ( $p>0.05)$.

Sonuç- Uzun dönemde oldukça fazla olumsuz etkisi olan sosyal damgalanma algısının azaltılması için sağlık çalışanlarına benlik duygusunu geliştirecek çalışmalar yapılması gerektiği düşünülmektedir. Sağlık hizmetlerinin sunulması sürecinde hizmet kalitesinin sürdürülebilmesi noktasında ana aktör olan sağ ıık çalışanlarında olumsuz duygu ve düşüncelerin azaltılmasının son derece önemli olduğu unutulmamalıdır.

Anahtar Kelimeler: COVID-19, pandemi, sağlık çalışanı, sosyal damgalanma.

JEL Kodları:. I12, I14, I18 


\section{GíRiş}

Sosyal damgalanma, çeşitli nedenlerle toplum içinde bazı grupların dışlanmasıyla ortaya çıkan bir durumdur. Bu durum dil, din, ırk, engellilik gibi nedenlere bağı ılarak ortaya çıktığı gibi hastalıklar dolayısıyla da ortaya çıkabilmektedir. Salgın sürecinde ve sonras ında yaşanan ve olumsuz sonuçların ortaya çıkmasına neden olan sosyal damgalanma, hastalık geçiren bireyler için olduğu gibi sağlık çalışanları açısından da önemli bir risk faktörüdür.

\section{LITERATÜR INCELEMESI}

Sosyal damgalanmanın ortaya çıkmasına ve damgalanan kişilerin ortaya koyduğu tepkilere neden olan çeşitli faktörler bulunmaktadır. Bu faktörler; farklı inanç sistemleri, kültürler, alt kültürler, sosyal kapasite, kimlik ve aile yapısı olabilmektedir (Doğanavşargil-Baysal, 2013). Sosyal damgalanma, damgalanmaya konu olan karakteristik unsuru temel alan bir gruplaşma oluşturmaktadır. Örneğin; hasta olanlar ve hasta olmayanlar şeklinde ortaya çıkan bu kesin ayırım, "biz" ve "onlar" anlayışını ortaya çıkarmaktadır. Biz duygusu güçlendikçe öteki ile ilgili güçsüzlük ve iktidarsızlık duygusu yaratılmaktadır. Hastalığa bağlı damgalanmanın oluşturduğu olumsuz etki, a rtan bilgi ve tıbbi teknolojiyle bile kolayca kaldırılamamaktadır. Çoğunluk olarak "biz" ve azınlık olarak "onlar" algısı yaratan sosyal damgalama, topluma yönelik zararı davranışların ortaya çıkmasıyla sonuçlanmaktadır (Williams ve Gonzalez 2011). Sosyal damgalanma, damgalanan kişilerin çalışma arkadaşları ve komşuları gibi yakın çevresinde bulunan kişilerden uzaklaşmasına neden olmaktadır. Kişinin kendisini topluma ait hissetmem esine varan sonuçları olan sosyal damgalanma önemli bir durumdur (Çam ve Çuhadar, 2011). Oysa sosyal damgalanmanın ortaya çıkardığı olumsuz sonuçların algılanan sosyal destekle neredeyse tersi yönde olduğunu söylemek mümkündür. Hatta algılanan sosyal desteğin genel sağlık durumu ile olumlu yönde ilişkili olduğu yönünde de literatür de kanıtlar bulunmaktadır (Liu ve ark., 2020).

Sosyal damgalanma uzun vadede pek çok olumsuz sonucun ortaya çıkmasına da neden olmaktadır. Bazı durumlarda sosyal damgalanma korkusu tedavi talebinde bulunmamaya bile neden olabilmektedir (Brooks ve ark., 2020; Verma ve ark., 2004; Maunder ve ark., 2003; Williams ve Gonzalez 2011). Sosyal damgalanma maaalesef bazen eğitimli olunmasına rağmen akılcı olmayan bir şekilde sürmektedir. (Williams ve Gonzalez 2011). Hatta sağlık çalışanları arasında bile görülebilmek te ve hastalık dolayısıyla sosyal damgalanma riski taşıyan hastaları topluma karşı korumak noktasında hassas olan sağlık çalışanları açısından daha zorlayıcı bir hale gelmektedir (Çam ve Çuhadar, 2011; Doğanavşargil-Baysal, 2013; Brooks ve ark., 2020). Sağlık çalışanlarının özgecilik tutumunu sürdürebilmesi noktasında güçlendirilmesinin önemli olduğu unutulmamalıdır (Chua ve ark., 2004). Bu nedenle daha büyük bir özveriyle çalıştıkları salgın sürecinde sağlık çalışanlarının karşı karşıya olduğu sosyal damgalanma riskinin değerlendirilmesi ile literatüre katkı sağlanacağına inanılmaktadır.

\section{VERI VE YÖNTEM}

Araştırma, elektronik soru formu aracılığıyla gerçekleştirilmiştir. Toplamda 151 katılımcıya ulaşılmış ve sonraki süreçte ver i analize hazır hale getirilmiştir. Araştırmada yer alan ifadeler arasındaki ters ifadeler dönüştürülmüştür. Katılımcıların ifadeleri 5'li Likert Ölçeği ile '5-Kesinlikle doğru, 1-Kesinlikle yanlış' aralığında yanıtlamaları istenmiştir. Anket formundan elde edilen veri, IBM SPSS 24.0 paket programı ile analiz edilmiştir. Yapılan analizler, tanımlayıcı istatistiklerin yanı sıra açıklayıcı faktör analizleri, korelasyon analizleri ile t-Testi, ve varyans analizidir (ANOVA). Parametrik ve parametrik olmayan testlerin seçiminde değişkenler için yapılan normallik testlerinde basıklık ve çarpıklık değerlerine göre karar verilmiştir.

Literatürde sağlık çalışanlarının salgın sürecinde sosyal damgalanma yaşadığına dikkat çeken bulgulara rastlanmış olmakla birlikte, sosyal damgalanmayı değerlendirmek üzere oluşturulmuş bir ölçeğe rastlanmamıştır. Bu nedenle araştırma için sosyal damgalanmayı değerlendirmek için literatür bilgisi, sağlık çalışanlarının bu konuda yaşadığı deneyimlerden ve basına yansıyan olaylardan yola çıkılarak 20 adet ifade oluşturulmuştur. Faktör analizi sonucunda elde edilen dört boyut mantıksal çerçeveye uygun şekilde oluşmuştur. Çalışmada faktör analizi sonucunda oluşan boyutların ifadelerle uygunluğu değerlendirilmiş ve adlandırımıştır. Faktör analizi sürecinde bir ifade değerlendirme dışında bırakılmış olup 19 ifadenin dört faktör altında toplandığı görülmüştür. Ölçeğin toplam güvenilirlik değeri 0,86 olup, sosyal damgalanma, mesleki saygınlık, dışlanma ve damgalanmaya şahit olma boyutları için güvenilirlik değerleri sırasıyla; 0,$91 ; 0,89 ; 0,74$ ve 0,75 şeklindedir. Belirtilen değerle Cronbach alfa değerleridir. Araştırmada kullanılan bütün ifadeler analiz sonucunda elde edilen değerlerle birlikte ilgili tablolarda sunulmuştur.

\section{BULGULAR}

Araştırmada yer alan katılımcıların demografik verileri Tablo 1'de gösterilmektedir. Katılımcıların ağırlıklı olarak 26-35 yaş aralığında olduğu görülmektedir. Katılımcıların \% 72'si kadın olup, \% 67,5'i evlidir. Eğitim durumu açısından değerlendirildiğinde katılımcılar ağırlıklı olarak \% 63,6 oranında lisans mezunudur (Tablo 1).

Boyutlar arası ilişkiler değerlendirildiğinde ölçeğin toplam puanı ile boyutların toplam puanla korelasyonun genel olarak orta ve yüksek

düzeyde olduğu görülmektedir. Ancak mesleki saygınlık boyutunun diğer boyutlarla korelasyon göstermemektedir. Bu durum, diğer boyutlarda yer alan ifadelerin tamamının damgalanmayla doğrudan ilişkilendirilebilecek ifadelerden oluşmasıyla açıklanabilir. Yapılan T-testi sonuçları, cinsiyete ve medeni duruma göre farklııı bulunmadığını, ANOVA Testi sonuçları da yaş gruplarına ve eğitim durumuna göre farklılaşma olmadığını göstermektedir ( $p>0.05$ ). 


\begin{tabular}{|c|c|c|c|c|c|}
\hline & $\mathbf{N}$ & $\%$ & & $\mathbf{N}$ & $\%$ \\
\hline Yaş & & & Medeni Durum & & \\
\hline $18-25$ yaş & 10 & 6,6 & Evli & 102 & 67,5 \\
\hline $26-35$ yaş & 49 & 32,5 & Bekar & 49 & 32,5 \\
\hline $36-45$ yaş & 75 & 49,7 & Eğitim Durumu & & \\
\hline$>45$ yaş & 17 & 11,3 & Lise/Ön lisans & 40 & 26,5 \\
\hline Cinsiyet & & & Lisans & 96 & 63,6 \\
\hline Kadın & 109 & 72,2 & Yüksek Lisans/Doktora & 15 & 9,9 \\
\hline Erkek & 42 & 27,8 & & & \\
\hline
\end{tabular}

Demografik değişkenlerle boyutlar arasındaki ilişkileri gösteren tablo aşağıda sunulmuştur:

\begin{tabular}{|c|c|c|c|c|c|c|c|}
\hline & Yaş & Cinsiyet & $\begin{array}{l}\text { Medeni } \\
\text { Durum }\end{array}$ & $\begin{array}{l}\text { Sosyal Ölçeği } \\
\text { Toplam Puan }\end{array}$ & $\begin{array}{c}\text { Sosyal } \\
\text { Damgalanma }\end{array}$ & $\begin{array}{l}\text { Mesleki } \\
\text { Saygınlık }\end{array}$ & $\begin{array}{l}\text { Damgalanmaya } \\
\text { Şahit Olma }\end{array}$ \\
\hline $\begin{array}{l}\text { Sosyal Ölçeği Toplam } \\
\text { Puan }\end{array}$ & $-0,013$ & 0,116 & 0,014 & & & & \\
\hline Sosyal Damgalanma & $-0,028$ & 0,047 & 0,028 & $0,833^{* * *}$ & & & \\
\hline Mesleki Saygınlık & 0,010 & 0,117 & $-0,037$ & $0,564^{* * *}$ & 0,111 & & \\
\hline Dışlanma & $-0,020$ & 0,083 & 0,019 & $0,695^{* * *}$ & $0,633^{* * *}$ & 0,040 & \\
\hline $\begin{array}{l}\text { Damgalanmaya Şahit } \\
\text { Olma }\end{array}$ & 0,005 & 0,052 & 0,069 & $0,555^{* * *}$ & $0,540^{* * *}$ & $-0,042$ & $0,414^{* * *}$ \\
\hline
\end{tabular}

Araştırma için oluşturulan ölçekte yer alan ifadelerin dört faktör oluşturduğu görülmektedir. İfadelerin faktör yükleri 0,50’ nin üstündedir. Bu faktörler; altında yer alan ifadeler ve faktör yükleriyle birlikte Tablo 2' de sunulmuştur. Ölçeğin açıklayıcılı̆̆ı toplamda \% 66,7 olup, faktörlerin ve ölçeğin toplam güvenilirlik değerlerinin de oldukça uygun olduğu görülmektedir (Tablo 3). 


\section{SONUÇ}

Bu araştırmada elde edilen bulguların genel olarak literatürle uyumlu olduğu söylenebilir. Açıkel ve Pakyüz (2015) tarafından yapılan çalışma hastaların damgalanma algısının cinsiyet ve medeni duruma göre farklılaşmadığını ortaya koymaktadır. Eski hükümlülerle gerçekleştirilen başka bir çalışmanın sonuçları da damgalanma algısının yaş ve eğitim değişkenlerine göre farklılaşmadığını ortaya koymaktadır (ArslanoğluÇetin, 2016). Yalçınay'ın (2015) kanser hastaları ile gerçekleştirdiği çalışmada da damgalanma algısı cinsiyete göre farklıla şmamaktadır. Ancak aynı çalışmanın sonuçları eğitim durumunun ayrımcılık anlayışı ile olumsuz yönde ve düşük düzeyde ilişkili olduğunu ortaya koy maktadır. Demirkıran (2019)'ın çalışması da cinsiyete, eğitim durumuna ve medeni duruma göre içselleştirilmiş damgalanma algısının farklılaşmadığını göstermektedir. Karslıoğlu (2018)’nun çalışması ise hastalıkları dolayısıyla erkeklerin daha fazla damgalanma kaygısı duyduğunu belirtmektedir.

Bu araştırmada elde edilen sonuç, sağlık çalışanlarının \% 51,2 oranda sosyal damgalanma yaşadığı yönündedir (Likert ölçeği ile değerlendirme 2,56/5). Hawryluck ve arkadaşları (2004) tarafından SARS Salgını sürecinde gerçekleştirilen çalışma karantina sonrasındaki süreçte karantinaya alınan kişilerin \% 51'i insanların kendilerinden kaçtığını, \% 29' u sosyal organizasyonlara davet edilmediğini, \% 7'si arkadaşları tarafından aranmadığını ve \% 7'si ailelerinin de kendilerinden dolayı bu toplantılara davet edilmediğini belirtmektedir. Değerlendirme kapsamında ele alınan değişkenler ve katılımcılar iki ar aştırmada da farklılaşıyor olmakla bir likte bu araştırma kapsamında elde edilen sonucun daha olumlu olduğunu söylemek mümkündür. Bu farklılaşma; kullanılan ölçeklerin, araştırmaların yapıldığı kültürlerin ve salgının boyutu gibi değişkenlerle birlikte değerşendirilmelidir. Bu bağlamda ülkemizdeki dayanışma anlayışının daha büyük ölçekte bir salgın yaşanmasına rağmen nispeten daha düşük düzeyde bir damgalanma algısı yaşandığı şeklinde yorumlanabilir. Mevcut araştırmalar sınırlı olduğ undan konuyla ilgili daha fazla ülke örneğiyle karşılaştırma yapılabilmesi, daha net sonuçların ortaya konmasını sağlayacaktır.

Bu çalışmada elde edilen ilginç bulgulardan biri de mesleki saygınlığın damgalanma algısı ile ilişkili olmamasıdır. Ancak literatürde benlik saygısının sosyal damgalanma algısını azaltacağı yönünde kanıtlar bulunmaktadır (Açıkel ve Pakyüz, 2015; Yakar, 2019). Bu bağlamda uzun dönemde oldukça fazla olumsuz etkisi olan sosyal damgalanma algısının azaltılması için sağlık çalışanlarıyla benlik duygusunu geliştirecek çalışmalar yapılması gerektiği düşünülmektedir. Örneğin sağlık çalışanlarının kendilerini psikolojik açıdan güçlü hissetmeler ini sağlayacak eğitimler planlanması gerekmektedir. Ayrıca toplumsal damgalamanın ortaya çıkma nedenleri ve olumsuz sonuçları konusunda toplumsal bilincin artırılması yönünde çalışmalar yapılması da önemlidir.

Çalışmada elde edilen bulgular doğrultusunda, sağlık hizmetlerinin sunulması sürecinde hizmet kalitesinin sürdürülebilmesi noktasında ana aktör olan sağlık çalışanlarında sosyal damgalanma nedeniyle yaşanabilecek olumsuz duygu ve düşüncelerin azaltılması yönünde önlemler alınması önerilmektedir. Bu doğrultuda sağlık çalışanlarının benlik duygusunun ve toplumun bilinç düzeyinin artırılması yönünde çalışmalar yapılmalıdır. 


\begin{tabular}{|c|c|c|c|c|c|c|}
\hline 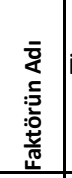 & \multicolumn{2}{|c|}{ ifadeler } & \multirow[t]{2}{*}{ 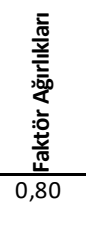 } & 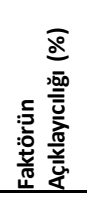 & 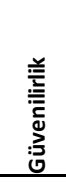 & 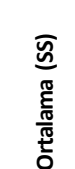 \\
\hline \multirow{6}{*}{ 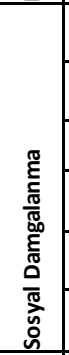 } & 14 & Salgın sürecinde çevremdeki insanların sağıı çalışanı olmamdan dolayı benden kaçıığıı hissettim. & & \multirow{6}{*}{32,0} & \multirow{6}{*}{0,91} & \multirow{6}{*}{$\begin{array}{c}2,68 \\
(0,99)\end{array}$} \\
\hline & 18 & Sağıık çalışanı olmak, bu süreçte çevremdeki insanların tutum ve davranışları açııından benim için zorlayıııydı. & 0,76 & & & \\
\hline & 16 & Inssanların sağ|ık çalışanlarına karşı aşııı tedbirli olması beni oldukça rahatsıı etti. & 0,76 & & & \\
\hline & 15 & $\begin{array}{l}\text { Sağılık çalışanı olduğum için insanlar enfekte olmak korkusuyla bana ve aileme karşı makul sınırları aşan bir } \\
\text { mesafe koydular. }\end{array}$ & 0,75 & & & \\
\hline & 10 & Sağ|ık çalışanı olduğumu öğrenen insanların benden uzak durmaya çalıştığııı hissettim. & 0,73 & & & \\
\hline & 17 & Çevremde enfekte birisinin bulunması benim de aynı olumsuz tepkileri sergilememe neden olurdu. & 0,69 & & & \\
\hline \multirow{7}{*}{ 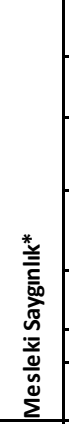 } & 7 & Salgın sürecinde insanlar bana karşı her zaman olduğundan daha duyarlı bir yaklaşım sergiledi. & 0,87 & \multirow{7}{*}{22,9} & \multirow{7}{*}{0,89} & \multirow{7}{*}{$\begin{array}{r}2,33 \\
(0,87)\end{array}$} \\
\hline & 4 & $\begin{array}{l}\text { Toplumun salgın sürecindeki sağlık çalışanları ile ilgili olumlu yaklaşımı mesleğim konusunda gurur duymamı } \\
\text { sağladı. }\end{array}$ & 0,85 & & & \\
\hline & 8 & Salgın sürecinde hissettiklerimin mesleğime olan bağılığımı arttırdığını düşünüyorum. & 0,82 & & & \\
\hline & 3 & Salgın sürecinde sağık çalışanı olmak benim olumlu duygular hissetmemi sağladı. & 0,78 & & & \\
\hline & 5 & Insanların sağlık çalışanlarıyla ilgili olumlu yaklaşımıyla ilgili samimi olduğunu düşünüyorum. & 0,76 & & & \\
\hline & 2 & Komşularımdan genel olarak olumlu bir yaklaşım gördüm. & 0,67 & & & \\
\hline & 6 & Salgın sürecinde sağılık çalışanı olmam dolayısıyla çeşitli jestlerle (ikramlar veya ayrıcalıklar , gibi) karşılaştım. & 0,67 & & & \\
\hline \multirow{4}{*}{ 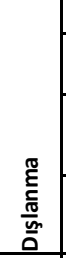 } & 12 & Sağlık çalışanı olduğum için bazı hizmetlerden faydalanamadım. & 0,76 & \multirow{4}{*}{6,1} & \multirow{4}{*}{0,74} & \multirow{4}{*}{$\begin{array}{r}2,48 \\
(0,85)\end{array}$} \\
\hline & 11 & Sağlık çalışanı olduğum için bazı hizmetlerden gecikmeli bir şekilde faydalanabildim. & 0,73 & & & \\
\hline & 9 & Yaşadığım yerde market alışverişi yaparken satııının benden kaçındığııı hissettim. & 0,59 & & & \\
\hline & 13 & $\begin{array}{l}\text { Sağılık çalışanı olmam dolayısıyla bazı ürünleri ve hizmetleri almak noktasında daha özenli davranıldğnı } \\
\text { hissettim. }\end{array}$ & 0,53 & & & \\
\hline \multirow{8}{*}{ 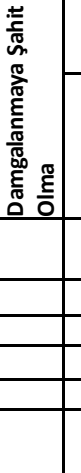 } & 20 & Hasta olduğu için damgalanma yaşadığını söyleyen hastalar oldu. & 0,77 & \multirow[b]{2}{*}{5,7} & \multirow[b]{2}{*}{0,75} & \multirow[b]{2}{*}{$\begin{array}{c}3,17 \\
(1,15)\end{array}$} \\
\hline & 19 & Çevremde hastalığı dolayısıyla sosyal açıdan olumsuzluklar yaşayanlara şahit oldum. & 0,71 & & & \\
\hline & & Toplam= & & 66,7 & 0,86 & $\begin{array}{c}2,56 \\
(0,63) \\
\end{array}$ \\
\hline & & $\mathrm{KMO}=$ & 0,841 & & & \\
\hline & & Bartlett Küresellik Test & & & & \\
\hline & & Ki Kare= & & 841 & & \\
\hline & & $\mathrm{Sd}=$ & 171 & & & \\
\hline & & & $<0,001$ & & & \\
\hline
\end{tabular}




\section{KAYNAKLAR}

Açıkel, G. Y., \& Pakyüz, S. Ç. (2015). Akciğer tüberkülozlu hastalarda damgalamanın değerlendirilmesi. FN Hem. Dergisi, 23(2), 136-145.

Arslanoğlu-Çetin Ece (2016) Koşullu Salıverme İle Tahliye Olmuş Hükümlülerde Damgalanma Algısı ve Damgalanma İle Başa Çıkma Stratejileri Arasındaki İlişki T.C. İstanbul Üniversitesi Adli Tıp Enstitüsü Sosyal Bilimler Anabilim Dalı Yüksek Lisans Tezi, İstanbul.

Brooks, S. K., Webster, R. K., Smith, L. E., Woodland, L., Wessely, S., Greenberg, N., \& Rubin, G. J. (2020). The psychological impact of quarantine and how to reduce it: rapid review of the evidence. The Lancet.

Chua, S. E., Cheung, V., McAlonan, G. M., Cheung, C., Wong, J. W., Cheung, E. P., .. \& Lee, P. W. (2004). Stres and psychological impact on SARS patients during the outbreak. The Canadian Journal of Psychiatry, 49(6), 385-390.

Çam, O., \& Çuhadar, D. (2011). Ruhsal hastalığa sahip bireylerde damgalama süreci ve içselleştirilmiş damgalama. Psikiyatri Hemşireliği Dergisi, 2(3), 136-140.

Demirkıran Bedriye Cansu (2019) Sedef Hastalarında İçselleştirilmiş Damgalanma Ve Yaşam Kalitesinin Değerlendirilmesi T.C. Atatürk Üniversitesi Sağlık Bilimleri Enstitüsü, İç Hastalıkları Hemşireliği Anabilim Dalı Yüksek Lisans Tezi, Erzurum.

Doğanavşargil-Baysal, G. Ö. (2013). Damgalanma ve ruh sağlığı. Arşiv Kaynak Tarama Dergisi, 22(2), $239-251$.

Hawryluck, L., Gold, W. L., Robinson, S., Pogorski, S., Galea, S., \& Styra, R. (2004). SARS control and psychological effects of quarantine, Toronto, Canada. Emerging Infectious Diseases, 10(7), 1206.

Karslıoğlu Sena (2018) The Experience of Receiving a Tuberculosis Diagnosis and Stigmatization: A Qualitative Study. İstanbul Bilgi University Institute of Social Sciences Clinical Psychology Master's Degree Program, İstanbul

Liu, X., Shao, L., Zhang, R., Wei, Y., Li, J., Wang, C., ... \& Zhou, F. (2020). Perceived Social Support and Its Impact on Psychological Status and Quality of Life of Medical Staffs After Outbreak of SARS-CoV-2 Pneumonia: A Cross-Sectional Study.

Maunder, R., Hunter, J., Vincent, L., Bennett, J., Peladeau, N., Leszcz, M., \& Mazzulli, T. (2003). The immediate psychological and occupational impact of the 2003 SARS outbreak in a teaching hospital. Cmaj, 168(10), 1245-1251.

Verma, S., Mythily, S., Chan, Y. H., Deslypere, J. P., Teo, E. K., \& Chong, S. A. (2004). Post-SARS psychological morbidity and stigma among general practitioners and traditional Chinese medicine practitioners in Singapore. Ann Acad Med Singapore, 33(6), 743-8.

Williams, J., \& Gonzalez-Medina, D. (2011). Infectious diseases and social stigma. Applied Innovations and Technologies, 4(1), 58-70.

Yakar Canan (2019) Ruhsal Hastalıklarda İçselleştirilmiş Damgalanma ve Benlik Saygısı Üzerine Bir Meta Analiz Çalışması, T.C. Çağ Üniversitesi Sosyal Bilimler Enstitüsü Psikoloji Ana Bilim Dalı, Yüksek Lisans Tezi, Mersin.

Yalçınay Merve (2015) Discrimination and Grief Symptoms in Cancer Patients Republic of Turkey Bahceşehir University Graduate School of Social Sciences Clinical Psychology Perceived Stigmatization İstanbul. 